Quim. Nova, Vol. 34, No. 9, 1666-1671, 2011

\title{
A FORMAÇÃO DOS DOCENTES DE QUÍMICA: UMA PERSPECTIVA MULTIVARIADA APLICADA À REDE PÚBLICA DE ENSINO MÉDIO DE GOIÁS
}

\author{
Deangelis Damasceno, Mariana da S. Godinho, Marlon H. F. B. Soares e Anselmo E. de Oliveira* \\ Instituto de Química, Universidade Federal de Goiás, CP 131, 74001-970 Goiânia - GO, Brasil
}

Recebido em 21/12/10; aceito em 15/4/11; publicado na web em 29/6/11

\begin{abstract}
CHEMISTRY TEACHER FORMATION: A MULTIVARIATE PERSPECTIVE APPLIED TO PUBLIC HIGH SCHOOLS IN THE STATE OF GOIÁS, BRAZIL. This paper presents a multivariate statistical analysis as a valuable tool for educational management applied to public high school chemistry teacher formation. From 2003 to 2007, a decrease of $10 \%$ in the number of public high schools was seen, as well as a reduction of $7 \%$ in the number of teachers. Contrarily, there was an increase in the number of university graduate teachers. Principal Component Analyses reveal that in 2003, most chemistry teachers were not university graduates. In 2007, eight Regional Offices of Education reported teachers holding academic degrees, qualifying them as chemistry teacher in the school system.
\end{abstract}

Keywords: teacher formation; chemical education; chemometrics.

\section{INTRODUÇÃO}

A formação do professor de Química no Brasil, especialmente daquele voltado ao ensino público em nível médio, e a sua permanência em um mercado de trabalho de pouco atrativo salarial representam algumas das preocupações da comunidade de pesquisadores da área de Ensino de Química, especialmente depois da edição da Lei 9.394/96, ${ }^{1}$ conhecida como Lei de Diretrizes e Bases da Educação (LDB). Um dos fatores que preocupam o escasso número de docentes que atuam na rede básica de ensino é a desvalorização profissional e social, o que acaba por levar profissionais graduados da área a atuarem em outros ramos profissionais, com um consequente desinteresse de futuros candidatos aos cursos de licenciatura, aumentando ainda mais esse problema. ${ }^{2}$

Outro fator que caracteriza a discussão sobre o tema está voltado para a qualidade acadêmica do professor de Química que atua no ensino médio. Atualmente, é pequena a quantidade de professores de Química, com licenciatura na área, atuantes nessa profissão especialmente na rede pública de ensino. O problema pode ser justificado pelo pequeno número de Instituições de Ensino Superior que oferecem cursos de formação de professores de Química, principalmente nas regiões Norte e Nordeste do $\mathrm{Brasil}^{3} \mathrm{e}$, dos poucos que existem, ainda é muito recente a preocupação em formar profissionais que estejam preparados para cumprir o papel social na formação da população..$^{4-6}$

Por outro lado, a formação de professores de Química também tem relação com os objetivos presentes em projetos pedagógicos dos cursos de licenciatura. Segundo Mesquita e Soares, ${ }^{7}$ os projetos pedagógicos dos cursos devem refletir que tipo de profissional se pretende formar. Em sua análise, a autora apresenta vários projetos pedagógicos para cursos de licenciatura que são, basicamente, cópias de projetos para cursos de bacharelado. Isso demonstra que muitos projetos de formação de professores ainda estão calcados na racionalidade técnica, correndo-se o risco de um curso de licenciatura refletir, na verdade, a formação de um bacharel. Essa situação é recorrente, pois apenas no final do século passado é que se deu início à discussão

*e-mail: elcana@quimica.ufg.br sobre como se deveria proceder à formação dos professores e quais os objetivos que deveriam ser alcançados por esses profissionais na sala de aula. ${ }^{8-10}$

A LDB se destaca dentre as várias medidas legais criadas para o aperfeiçoamento dos docentes. Essa lei estabeleceu o nível de formação superior dos docentes e está voltada para a profissionalização teórica e prática da licenciatura, articulada e distribuída em $2.800 \mathrm{~h} /$ aula, ${ }^{11}$ em um curso superior normal e regulamentado. ${ }^{12}$ Por outro lado, esse passo importante para a valorização profissional não veio aliado a uma política de valorização salarial ou, ainda, com um plano de carreira que pudesse atrair os jovens para a profissão docente.

A LDB, juntamente com o parecer CNE/CES No 1.303 de $06 / 11 / 2001,{ }^{13}$ que estabeleceu as diretrizes para formação nos cursos de Química, determinaram que para ministrar aulas em nível médio do ensino básico, o profissional deve ter curso superior de Licenciatura em Química. Essas determinações caracterizam-se por uma formação generalizada e abrangente, cujos conhecimentos são aplicados de forma pedagógica, contribuindo para a formação do aluno, tanto no trato cultural, quanto na visão investigativa e científica. ${ }^{14}$

No entanto, um dos maiores problemas a ser enfrentado pela educação no estado, e também em todo o país, para se adequar às medidas da LDB e aos Decretos-Leis 3.276/99 ${ }^{15}$ e 3.554/00, ${ }^{16}$ que dispõem sobre a formação em nível superior de professores para atuar na educação básica, é a falta de professores com formação em nível superior adequada para o ensino básico. Na área de Química no Brasil, essa formação não é um problema recente, seja pela quantidade ainda pequena de cursos de formação, seja pela má remuneração característica da profissão, principalmente no ensino médio público, o que torna a carreira pouco atraente. Como resultado direto, a enorme desistência por parte dos profissionais especializados em diversas disciplinas ${ }^{17}$ é um dos grandes problemas enfrentados pelas instituições de ensino básico, principalmente as de personalidade jurídica pública. Nesse caso, as vacâncias das áreas curriculares são substituídas por outros profissionais com conhecimentos específicos reduzidos. ${ }^{18}$

Outras orientações pedagógicas, como as Orientações Curriculares Nacionais para o ensino Médio (PCNEM), ${ }^{19}$ têm uma grande preocupação com o que esse profissional, formado em curso supe- 
rior, pode vir a ministrar no ensino médio. Uma diretriz nacional de formação e uma orientação curricular para esse professor são consequências da preocupação em se formar licenciados conscientizados e especializados, capazes de desenvolverem suas práticas docentes em prol da sociedade ao seu redor, principalmente quando atuam no ensino básico.

No estado de Goiás, a realidade em termos de formação e atuação desse professor na rede pública não é muito diferente do restante do país e, em alguns casos, bem pior. ${ }^{20}$ Nos últimos anos, o perfil desse profissional vem mudando de maneira contínua em termos da sua formação, ${ }^{21}$ principalmente pelo número de universidades, faculdades e Institutos Federais criados e locados no estado. ${ }^{22}$ Todos os professores, sejam efetivos ou contratados temporariamente, ${ }^{23}$ são modulados nos 246 municípios $^{24}$ do estado pela ação das Subsecretarias Regionais de Ensino (SREs) que, criadas pelos decretos n. ${ }^{\circ} 5.444 / 01^{25}$ e n. ${ }^{\circ}$ $5.974 / 042,{ }^{26}$ se tornaram departamentos ligados à Secretaria de Estado da Educação (SEE-GO). ${ }^{27}$ Em 2007 havia 37 SREs, enquanto que a partir de 2008 esse número passou para 38. Essas SREs descentralizam o controle da SEE-GO por todo o estado de Goiás.

Considerando a formação de professores no estado de Goiás, bem como a distribuição dos profissionais nas várias SREs, o presente manuscrito propõe uma nova aplicação da ferramenta quimiométrica de análise de componentes principais ${ }^{28}$ (PCA), especificamente para a avaliação da formação docente na área de Química para o nível médio de ensino, tanto nos aspectos quantitativos, como qualitativos. O emprego de uma ferramenta quimiométrica altamente eficaz na determinação dos problemas de formação e de distribuição dos professores em determinados ambientes - especificamente o Estado de Goiás -, pode contribuir para explicar algumas situações encontradas, baseando-se no contexto social, profissional e tecnológico atual. Assim, este artigo aborda as mudanças ocorridas na formação desses docentes, utilizando-se de uma ferramenta estatística, PCA, para analisar o perfil da formação dos professores de Química e as mudanças ocorridas entre 2003 e 2007, de modo multivariado, para todas as SREs do Estado.

\section{METODOLOGIA}

Os dados empregados neste trabalho foram fornecidos pela SEEGO e são referentes aos anos de 2003 e 2007. Esses dados constam dos Módulos Escolares que contêm, entre outras informações, o nome completo do servidor, seu número de matrícula, a SRE de ensino, o cargo ocupado, a quantidade de aulas ministradas, o nome da escola de modulação, o nome da escola de extensão de carga horária, o número de matrícula da escola, o município no qual o professor está modulado, a formação profissional e o nível de carreira do docente. ${ }^{21}$ Esses módulos foram digitalizados e separados por ano, o que resultou num total de 75 planilhas ( 37 planilhas para 2003 e 38 para 2007, conforme o número de SREs em cada um dos anos avaliados) usadas na construção da matriz de dados referentes à formação dos professores. Os valores nessas tabelas foram apresentados como percentual em relação ao total de professores de Química modulados nas secretarias para cada ano.

Os anos de 2003 e 2007 foram escolhidos, levando-se em conta que os últimos concursos públicos para contratação de professores no estado de Goiás ocorreram nesse período. No início de 2010, outro concurso foi realizado. Porém, como os professores ainda não foram modulados nas SRES, esses dados não puderam ser considerados neste trabalho.

A técnica quimiométrica utilizada é a PCA, uma ferramenta multivariada empregada para classificar os dados sobre a formação dos professores no estado de Goiás e, também, para analisar padrões e tendências na variabilidade das formações dos professores para os anos de 2003 e 2007. A escolha dessa ferramenta deve-se à necessidade de se estabelecer uma comparação da variabilidade espacial e temporal entre os vários dados coletados para as SREs. Esse método permite a redução da dimensionalidade dos dados originais, o que possibilita a visualização dos dados em gráficos bidimensionais.

Os resultados são expressos em gráficos cujos eixos são as duas primeiras Componentes Principais, onde são representados os escores para cada SRE. Esses escores são as projeções dos dados originais nesses novos eixos, chamados de Componentes Principais. Em conjunto ao gráfico dos escores, o gráfico dos pesos é representado no mesmo sistema de coordenadas, os quais refletem a importância das variáveis nas Componentes Principais e são importantes na classificação por similaridade. Todo o tratamento matemático foi feito utilizando o programa $\mathrm{Scilab}^{29}$ e a rotina para PCA foi utilizada conforme consta na ref. 30 .

\section{RESULTADOS E DISCUSSÃO}

Em 2003 a SEE-GO administrava 1.223 escolas públicas de educação básica, ${ }^{27}$ aonde atuavam 29.701 professores, entre efetivos e temporários. Desses, 823 eram professores de Química, o que correspondia, aproximadamente, a 2,7\% do total. Desse pequeno percentual, apenas 24 docentes possuíam licenciatura em Química. Isto é, apenas 2,91\% dos professores atuantes na área de Química no estado de Goiás possuíam curso de licenciatura em Química. Já em 2007, segundo dados do Censo do INEP, ${ }^{31}$ o número de escolas públicas sob a tutela do estado diminuiu cerca de $10 \%$, para um total de 1.108 unidades, e o número de professores caiu para 27.812 professores lotados. O que representou uma queda de $6,4 \%$ em relação a 2003, conforme pode ser visualizado na Figura 1. Percebe-se nessa figura que entre 2000 e 2007 houve uma queda de quase $15 \%$ no número de professores do estado, mesmo com a realização de novos concursos no período.

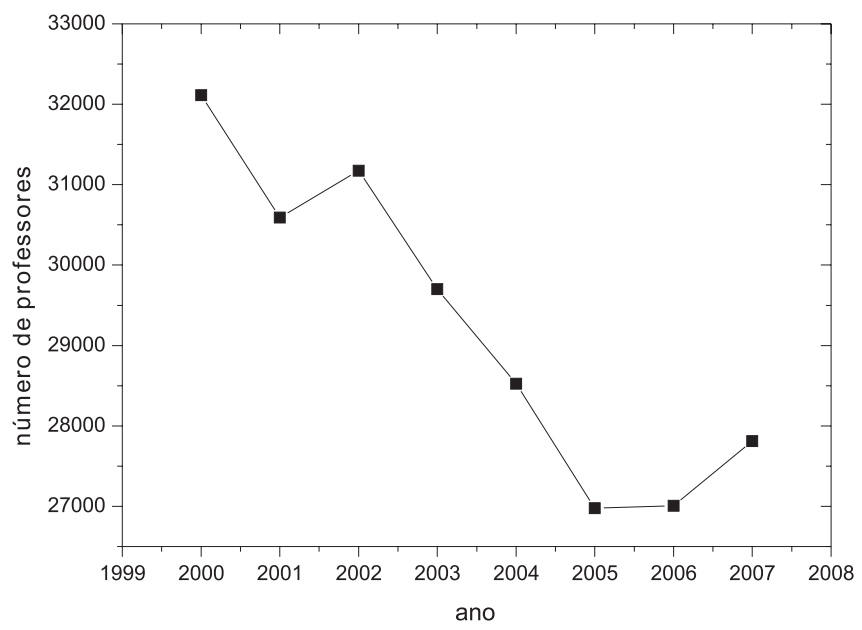

Figura 1. Gráfico do número de professores da rede de ensino público do estado de Goiás, entre os anos de 2000 a 2007

Em 2007 havia 148 professores com licenciatura em Química, o que correspondia a menos de $1 \%$ do total de professores e aproximadamente $15 \%$ dos profissionais modulados para lecionar a disciplina de Química em todo o estado, conforme a Tabela 1. Percebe-se, nesses dados, uma evolução no número total de professores modulados em Química de cerca de 25\% e um aumento de pouco mais de $600 \%$ no número de professores licenciados. Ou seja, houve uma evolução no quadro de docentes em Química na rede pública do ensino médio do estado com a entrada de professores efetivos, nível PIII, e de professores contratados temporariamente. 
Tabela 1. Número e percentual ${ }^{\mathrm{a}}$ de professores $^{\mathrm{b}}$ de Química da rede de ensino público do estado de Goiás, nos anos de 2003 e 2007

\begin{tabular}{lcc}
\hline & 2003 & 2007 \\
\hline Formação não cadastrada $^{c}$ & $275(33,4 \%)$ & $346(33,7 \%)$ \\
Licenciados em Química & $24(2,91 \%)$ & $148(14,4 \%)$ \\
$\begin{array}{l}\text { Total de professores modulados } \\
\text { em Química }\end{array}$ & 824 & 1028 \\
\hline
\end{tabular}

a) em relação ao total de professores de Química modulados para cada ano; b) modulados como Escolaridade Superior Completa nos Módulos Escolares; c) informação não cadastrada pela SEE-GO nos Módulos Escolares.

Porém, apesar do alto crescimento no número de professores com nível PIII (efetivo, com habilitação específica em nível superior de licenciatura plena), a situação ideal ainda está longe de ser alcançada, especialmente quando são avaliadas as diferentes formações acadêmicas. Na Tabela 2 constam as formações dos professores de Química conforme definidas nos Módulos Escolares. Percebe-se, nessa tabela, que não são apenas os profissionais com formação em áreas afins à Química, como Física e Biologia, que lecionam Química, mas também professores com o nível supletivo, além de graduados em Violino, por exemplo. Cabe, como adendo, o fato de que muitos profissionais não tiveram sua formação cadastrada. $\mathrm{Ou}$ seja, são profissionais que lecionam Química, mas que a SEE-GO não tem conhecimento/cadastro da formação desse professor. E esses profissionais representam a maioria dos professores de Química, conforme pode ser verificado na Tabela 1 .

Em termos da formação dos professores, a situação não mudou tanto nos últimos anos. Ao final de 2009, menos de 200 professores licenciados em Química estavam modulados como professores de Química. Dados preliminares de 2010 mostram cerca de 230 professores.

\section{Análise de componentes principais}

Os dados referentes à formação dos professores para os anos de 2003 e 2007, fornecidos pela SEE-GO, foram agrupados em 7 categorias, consideradas como variáveis na PCA. Essas variáveis constam da Tabela 3, sendo que o número de professores em cada categoria da SEE-GO foi utilizado para montar as matrizes de dados de tamanhos ( 37 x 7) e (38 x 7), para 2003 e 2007, respectivamente. Nos Módulos Escolares, cerca de $33 \%$ dos docentes foram cadastrados como possuindo Escolaridade Superior Completa, ao invés da informação adequada sobre qual o tipo dessa formação. Esse resultado foi considerado como formação não cadastrada, conforme a Tabela 1.Is

Um dos requisitos básicos do estudo multivariado é a representatividade dos dados. ${ }^{32}$ Desse modo, conjuntos de dados mal estruturados formam modelos de regressão, ou de agrupamento, imprecisos e que levam a interpretações equivocadas. Em resultados experimentais obtidos em laboratórios, amostras anômalas (outliers) são excluídos ou substituídos. ${ }^{33}$ Já os dados obtidos em Educação não possuem essa facilidade. Logo, para extrair possíveis resultados desses conjuntos de dados, todos os profissionais que possuíam a classificação Escolaridade Superior Completa denominados, pela SEE-GO, de professores de nível PIII, foram agrupados na variável NEN, Tabela 3.

De posse dos dados contidos nos Módulos Escolares, e agrupados conforme a Tabela 3 foi realizada a PCA para a base de dados referentes a 2003. Os resultados dessa análise constam das Figuras 2 e 3, que representam praticamente metade da informação contida nos dados originais. Os números na Figura 2 referem-se às SREs e as letras na Figura 3 , às variáveis (Tabela 3 ).

A distribuição das SREs na Figura 2, gráfico dos escores, é consequência da maneira pela qual estão distribuídas as variáveis na Figura 3 , gráfico dos pesos. Por exemplo, percebe-se na Figura 2 que das 37 SREs, 20 encontram-se no lado direito, e de acordo com a Figura 3, essa á região do gráfico na qual as variáveis características são $C T$ e HBM, que correspondem a Cursos Técnicos e Habilitação Básica em Magistério, respectivamente. Isso significa que grande parte das SREs apresentava, em 2003, docentes de Química sem formação em nível superior. Eles eram considerados professores de nível PI (professores efetivos, com habilitação específica em nível médio, na modalidade normal) ou PA-C (professores com contrato temporário, com escolaridade em nível do ensino médio completo). Por exemplo, as SREs de Piracanjuba $\left(n^{\circ} 22\right)$ e Posse ( $\left.n^{\circ} 26\right)$, mais à direita na Figura 2, apresentavam 67 e $94 \%$ dos seus professores de Química com Habilitação Básica em Magistério, respectivamente. Na SRE de Piracanjuba, os $33 \%$ dos professores restantes possuíam nível técnico.

Nos extremos superior e inferior da Figura 2 estão as SREs cujos professores de Química possuem curso superior, conforme as posi-

Tabela 2. Formação dos professores de Química

\begin{tabular}{|c|c|c|c|c|c|}
\hline \multicolumn{2}{|c|}{ Nível Médio } & \multicolumn{4}{|c|}{ Nível Superior } \\
\hline Auxiliar Administrativo & HB $^{\text {a }}$ Saúde & $\mathrm{L}^{\mathrm{b}}$ Ed. Artística & L Ciências & L Geografia & Engenharia \\
\hline Ensino Médio & Teologia & Eng. Alimentos & Direito & Economia & L Biologia \\
\hline HB Contabilidade & Comunicação & L Estudos Sociais & L Física & Agronomia & Farmácia \\
\hline HB Magistério & Cursos Técnicos & L História & L Letras & L Matemática & Odontologia \\
\hline Ciências Econômicas & Supletivo & Veterinária & L Violino & Zootecnia & Psicologia \\
\hline HB Estatística & & Enfermagem & L Química & L Ed. Física & L Filosofia \\
\hline Organização Social Públi & & L Pedagogia & Administração & & \\
\hline
\end{tabular}

a) $\mathrm{HB}=$ Habilitação Básica; b) L = Licenciatura.

Tabela 3. Variáveis e categorias para as formações dos professores de Química

\begin{tabular}{lll}
\hline Variável & Categoria & Descrição \\
\hline$D H$ & Demais Habilitações & Formação básica de ensino médio diferente da habilitação em magistério \\
$C T$ & Cursos Técnicos & Habilitações técnicas e auxiliares de nível médio \\
$Q$ & Licenciatura em Química & Docentes com Licenciatura em Química \\
$C O L$ & Ensino Médio & Nível médio e supletivo \\
$N E N$ & Nenhuma formação cadastrada & Profissionais que não tiveram sua formação divulgada no Módulo Escolar \\
$D F S$ & Demais Formações de Ensino Superior & Formações diversas no ensino superior \\
$H B M$ & Habilitação Básica em Magistério & Docente em fase inicial de carreira \\
\hline
\end{tabular}




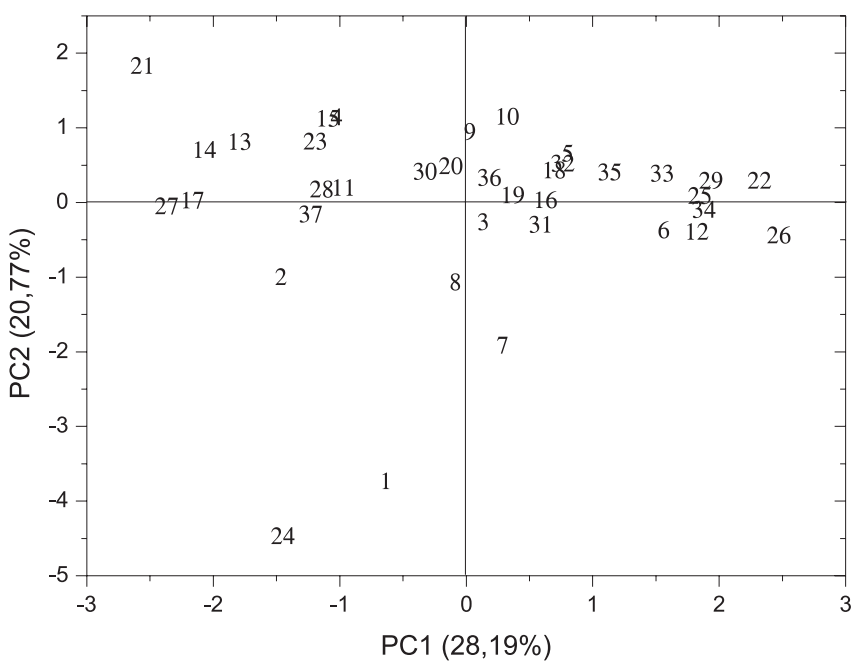

Figura 2. Gráfico dos escores das duas primeiras componentes principais para a base de dados de 2003. Esse gráfico explica cerca de $50 \%$ da variância total dos dados. Cada número refere-se a uma SRE

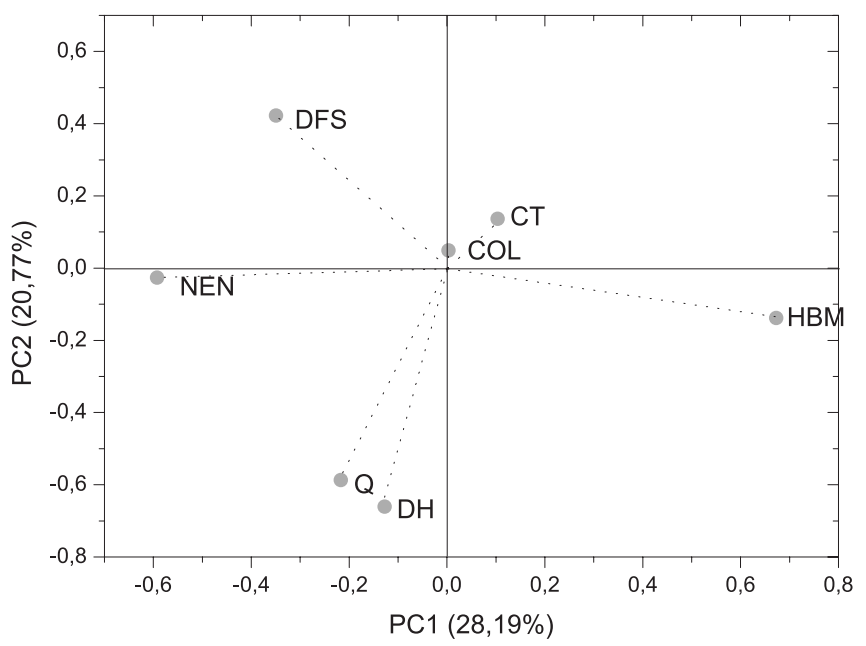

Figura 3. Gráfico dos pesos das duas primeiras componentes principais para a base de dados de 2003. Os símbolos estão de acordo com a Tabela 3

ções das variáveis $D F S, Q$ e $D H$ na Figura 3. Consequentemente, as SREs com os maiores percentuais de professores com licenciatura em Química, $Q$, e com Demais Habilitações, $D H$, estão na parte de baixo da Figura 2. Por exemplo, na SRE de Anápolis ( $\left.{ }^{\circ} 1\right)$ - cidade vizinha de Goiânia, aonde se encontra um dos campi da Universidade Estadual de Goiás e que também conta com um polo de formação em Química administrado pelo Serviço de Aprendizagem Industrial (SENAI) -, quase $17 \%$ dos professores possuíam licenciatura em Química. Apesar do baixo percentual dentre as SREs, essa era a que possuía o maior percentual de professores com essa formação. Outro exemplo é a SRE de Porangatu ( $\left.\mathrm{n}^{\circ} 24\right)$, que se encontra mais abaixo na Figura 2, e que vem em seguida com apenas 7\% dos professores com licenciatura em Química. Já na parte superior, à esquerda, estão as SREs que apresentavam altos níveis de professores com nível superior completo, DFS - no entanto, esses professores não possuíam licenciatura em Química. A SRE de Piranhas (nº 21), acima e à esquerda na Figura 2, possuía metade dos seus professores sob essa condição, enquanto que para a SRE de Jataí $\left(n^{\circ} 14\right)$ esse porcentual era de pouco menos de 20\%. Cabe ainda ressaltar que das 37 SREs que havia em 2003, apenas 6 possuíam professores de Química com licenciatura em Química, o que representava menos que 20\% das SREs.

No centro da Figura 2 estão as SREs que apresentam os maiores índices de professores com menor qualificação. Essa informação resulta da correlação com a posição das variáveis $C O L$ e $C T$ na Figura 3.

A PCA para a base de dados de 2007 resultou nos gráficos de escores e pesos conforme as Figuras 4 e 5, respectivamente, que representam cerca de $80 \%$ da informação dos dados originais. As variáveis mais importantes ocupam cada um dos quadrantes da Figura 5. De posse desses dois gráficos pode-se inferir, por exemplo, que a SRE de Goiânia ( $\left.{ }^{\circ} 17\right)$, localizada na parte inferior da Figura 4, está separada das demais em decorrência da importância da variável $Q$ na Figura 5. Ou seja, o percentual de licenciados em Química é uma característica importante dessa SRE. Essa conclusão pode ser confirmada pelo fato de que cerca de metade dos licenciados em Química se encontravam lecionando na capital.

As mudanças nos gráficos de escores entre 2003 e 2007, Figuras 2 e 4, respectivamente, refletem as alterações no perfil da formação do professor de Química do estado de Goiás. Na capital, Goiânia, SRE $n^{\circ} 17$, que na Figura 2 se encontra no lado esquerdo, aparece no lado de baixo da Figura 4, em decorrência do aumento do número de professores com licenciatura em Química no período. O percentual desses professores passou de 5\%, para quase metade do seu quadro docente em 4 anos. Em outras 22 SREs também se percebem essas

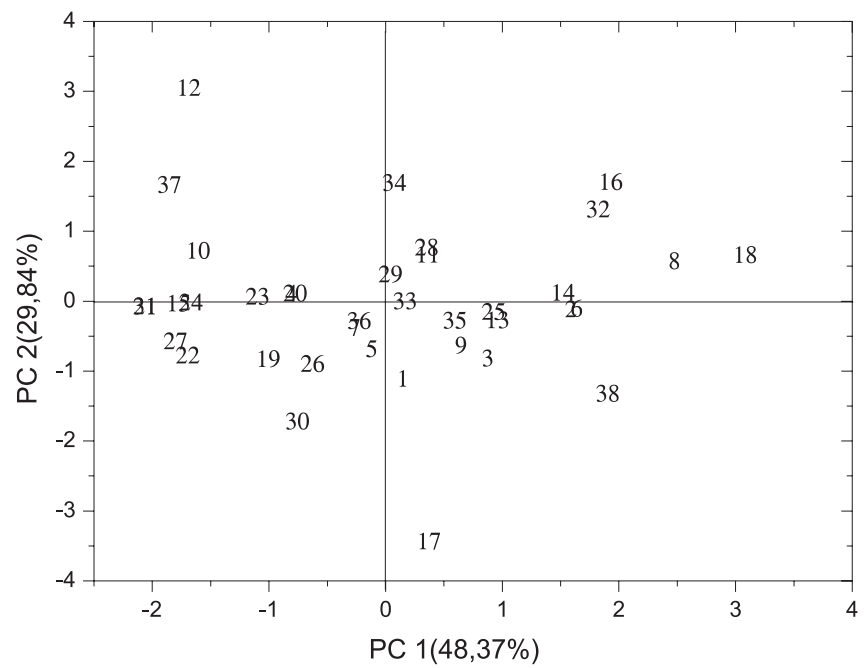

Figura 4. Gráfico dos escores das duas primeiras componentes principais para a base de dados de 2007. Esse gráfico explica cerca de $80 \%$ da variância total dos dados. Cada número refere-se a uma SRE

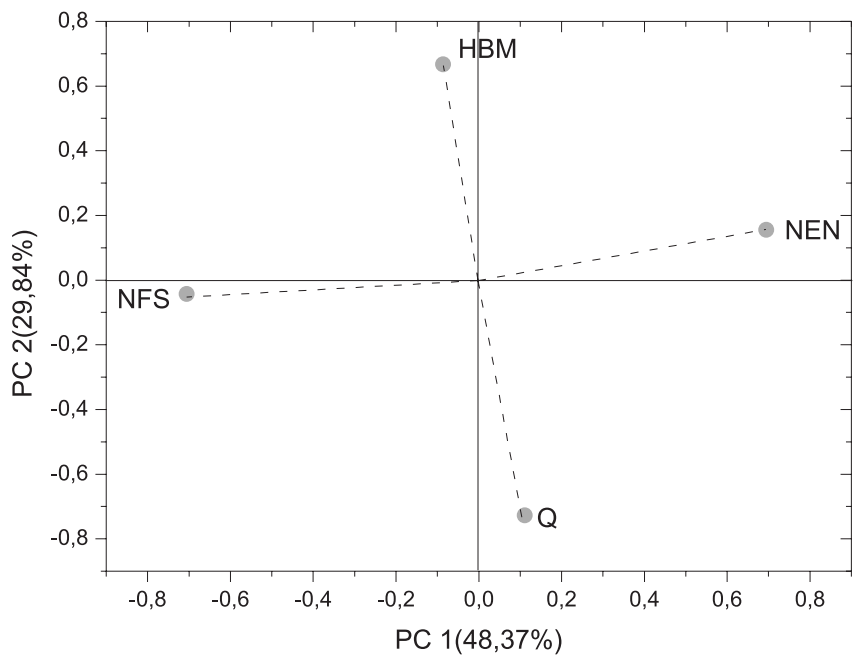

Figura 5. Gráfico dos pesos das duas primeiras componentes principais para a base de dados de 2007. Os símbolos estão de acordo com a Tabela 3 
alterações decorrentes do aumento do percentual de professores com licenciatura em Química. Na contramão, Inhumas ( $\left.n^{\circ} 8\right)$ e Porangatu $\left(n^{\circ} 24\right)$, que em 2003 tinham cerca de $6 \%$ de professores com licenciatura em Química, não apresentaram nenhum em 2007. Já outras 12 SREs continuaram sem professores com essa formação.

Uma suposição para o aumento do número de professores de Química na região metropolitana de Goiânia pode ser a migração do interior para a capital. Alunos oriundos do interior do estado após a graduação em nível superior procuram alternativas de emprego na capital do estado, ao mesmo tempo em que buscam novos horizontes profissionais ou, ainda, formação continuada.

Os resultados apresentados com base nas análises estatísticas revelam que as mudanças ocorridas entre 2003 e 2007 estão longe de terem sido ideais. O percentual de professores graduados em Licenciatura em Química passou de quase 3\% em 2003, para cerca de $15 \%$ em 2007 - uma taxa muito pequena levando-se em consideração que surgiram vários cursos de Licenciatura em Química, além da realização de processos seletivos no período. Apesar da mudança no quadro dos professores, a carência de professores de Química com licenciatura em Química ainda é muito grande. Mesmo com o surgimento de vários cursos de Licenciatura em Química, a SEE-GO não conseguiu atingir, em 2007, 1.028 professores efetivos com licenciatura na área, ou seja, esse número representa o número de vagas para professores de Química disponível à época. Há que se considerar que alguns professores acabam migrando para outras atividades, onde possuem melhores condições de trabalho e salário, tais como indústrias químicas, comércio varejista, além dos cursos de pós-graduação no estado e fora dele e, até mesmo, outra carreira universitária. $^{22}$

Com esses resultados, tanto para 2003 como para 2007, e por meio de dados do Centro de Seleção da UFG, responsável por vários concursos públicos no estado, podemos inferir que os profissionais com licenciatura em Química estão buscando outras atividades fora da sala de aula, tanto na cidade de origem, quanto em cidades vizinhas, além de buscarem formação continuada em nível de mestrado, exatamente para saírem da sala de aula.

Por um lado, com a ausência de profissionais da área de Química, de maneira geral no estado, sejam licenciados, sejam bacharéis, há uma migração dos licenciados que se encontravam em sala de aula para empresas públicas ou privadas em trabalhos de nível técnico que remuneram melhor. O próprio estado de Goiás contrata técnicos em química (10 no último concurso, exigência mínima: nível médio) em suas secretarias de saúde ou de meio ambiente, remunerando-os em cerca de $20 \%$ a mais do que o professor de nível superior contratado pela Secretaria de Educação. Contraditório. Desses 10 técnicos contratados, 50\% eram licenciados. A própria UFG absorveu 4 licenciados em seu quadro técnico de laboratório, que anteriormente estavam nas escolas.

Por outro lado, professores que se encontravam ministrando aulas no ensino médio procuraram formação continuada em nível de mestrado. Com o título em mãos, encontram-se contratados em Universidades e Institutos Federais, com melhores salários e condições de trabalho.

\section{CONCLUSÕES}

Entre 2003 e 2007, há uma diminuição do número de professores na rede pública de ensino médio no estado de Goiás e um aumento do número de professores licenciados em Química. No entanto, esse aumento ainda está longe do ideal. Com base nos resultados obtidos com a PCA, percebe-se que no ano de 2003 a maioria das SREs possuía professores de Química sem nível superior e com Habilitação Básica em Magistério. Já em 2007, tem-se outra realidade, onde 20\% das SREs contavam com professores com licenciatura em Química, e a SRE de Anápolis apresentava o maior percentual, com 17\%.

Nesse mesmo ano, cerca de $50 \%$ dos professores com licenciatura em Química eram lotados na SRE de Goiânia, seja pela relação migração/formação, seja pelas oportunidades de emprego. Cidades do interior do estado, com estruturas boas e ótimas, variando entre 60 e 200 mil habitantes também não têm muitos licenciados. Tais aspectos mostram a necessidade da interiorização de cursos de licenciatura em Química, evitando a migração de futuros professores. Concomitante a essa interiorização, o aumento e a melhoria dos cursos de licenciatura não podem vir separados de uma valorização profissional, além de um plano de carreira que possibilite um aumento da demanda pela área e torne a profissão docente mercadologicamente atraente para os jovens.

Finalmente, a ferramenta estatística de análise multivariada, PCA, pode ser empregada na análise de dados na área de educação, inclusive em outros estados, visto que não é restrita à realidade do estado de Goiás. O foco dessa abordagem, apesar de resultar do estudo de dados da rede pública de ensino em nível médio, acaba sendo o ensino superior e pode mostrar, com grande clareza e facilidade, regiões no estado aonde se faz necessária uma presença maior do poder público. Essa presença pode ser ampliada com a realização de concursos, ou com a abertura de novos cursos de Licenciatura em Química. Desse modo, PCA é, também, uma ferramenta que pode auxiliar na gestão educacional, na identificação de tendências ou mudanças no perfil dos profissionais da Educação, além de correlacionar essas mudanças com suas causas.

\section{MATERIAL SUPLEMENTAR}

As Tabelas $1 \mathrm{~S}$ e $2 \mathrm{~S}$ apresentam os dados usados na confecção dos gráficos das Figuras 2 a 5. Esse material encontra-se disponível em http://www.quimicanova.sbq.org.br, na forma de arquivo PDF, com acesso livre.

\section{AGRADECIMENTOS}

À FUNAPE e ao CNPq pelo apoio financeiro, e à Secretaria de Educação do Estado de Goiás pela disponibilização dos Módulos Escolares.

\section{REFERÊNCIAS}

1. https://www.planalto.gov.br/ccivil_03/Leis/L9394.htm, acessada em Junho 2011.

2. http://emaberto.inep.gov.br/index.php/emaberto/article/view/708/631, acessada em Junho 2011

3. Farias, S. A.; Ferreira, L. H.; Resumos do $6^{\circ}$ Simpósio Brasileiro de Educação Química, Fortaleza, Brasil, 2008.

4. Schnetzler, R. P.; Quim. Nova 2002, 25 (suplemento 1), 14.

5. Arroyo, M. G.; Educação e Sociedade 1999, 68, 143.

6. Santos, W. L. P.; Schnetzler, R. P.; Química Nova na Escola 1996, n. 4, 28.

7. Mesquita, N. A. S.; Soares, M. H. F. B.; Química Nova na Escola 2009, 31,123 .

8. Domingues, J. J.; Toschi, N. S.; de Oliveira, J. F.; Educação e Sociedade 2000, 21, 63 .

9. Scheibe, L.; Educere et Educare 2006, 1, 199.

10. Maldaner, O. A.; A Formação Inicial e Continuada de Professores de Química, Unijuí: Ijuí, 2000.

11. http://portal.mec.gov.br/cne/arquivos/pdf/CP022002.pdf, acessada em Junho 2011.

12. Tanuri, L. M.; Revista Brasileira de Educação 2000, 14, 61. 
13. http://portal.mec.gov.br/cne/arquivos/pdf/CES1303.pdf, acessada em Junho 2011.

14. http://portal.mec.gov.br/cne/arquivos/pdf/CP012002.pdf, acessada em Junho 2011

15. http://www010.dataprev.gov.br/sislex/paginas/23/1999/3276.htm, acessada em Junho 2011.

16. http://portal.mec.gov.br/sesu/arquivos/pdf/dec355499.pdf, acessada em Junho 2011

17. Tartuce, G. L. B. P.; Nunes, M. M. R.; Almeida, P. C. A.; Cadernos de Pesquisa 2010, 40, 445.

18. http://www.andifes.org.br/index.php?option=com_content\&task=view \&id=210\&Itemid=104, acessada em Junho 2011.

19. http://portal.mec.gov.br/index.php?option=com_content\&view=article \&id=13558:politicas-de-ensino-medio\&catid=195:seb-educacao-basica, acessada em Junho 2011.

20. O Popular, 2009, 13 de Julho, 3.

21. Damasceno, D.; Godinho, M. da S.; Soares, M. H. F. B.; de Oliveira, A. E.; Educación Química 2010, 21, 246.

22. Mesquita, N. A. S.; Tese de Doutorado, Universidade Federal de Goiás, Brasil, 2010

23. http://www.gabinetecivil.goias.gov.br/leis_ordinarias/2001/lei_13909. htm, acessada em Junho 2011

24. http://www.ibge.gov.br/estadosat/perfil.php?sigla=go, acessada em Junho 2011.
25. http://www.gabinetecivil.goias.gov.br/pagina_decretos.php?id=1544, acessada em Junho 2011.

26. http://www.gabinetecivil.goias.gov.br/pagina_decretos.php?id=1036, acessada em Junho 2011

27. http://www.see.go.gov.br/educacao/subsecretarias/index.asp, acessada em Junho 2011.

28. Sharaf, M. A.; Illman, D. H.; Kowalski, B. R.; Chemometrics, John Wiley \& Sons: New York, 1986; Godinho, M. S.; Pereira, R. O.; Ribeiro, K. O.; Schimidt, F.; de Oliveira, S. B.; de Oliveira, A. E.; Quim. Nova 2008, 31, 1727.

29. http://www.scilab.org, acessada em Junho 2011.

30. Ferreira, M. M. C.; Antunes, A. M.; Melgo, M. S.; Volpe, P. L. O.; Quim. Nova 1999, 22, 724 .

31. http://portal.inep.gov.br/todas-noticias?p_p_auth=UGGsOA1Z\&p_p_ id=56_INSTANCE_d9Q0\&p_p_lifecycle=0\&p_p_state=normal\&p_p_ mode $=$ view\&p_p_col_id=column- 2\&p_p_col_pos=2\&p_p_col_ count=3\&_56_INSTANCE_d9Q0_groupId=10157\&p_r_p_564233524_ articleId=15431\&p_r_p_564233524_id=15432, acessada em Junho 2011.

32. Araújo, T. P.; Tese de Doutorado, Universidade Estadual de Campinas, Brasil, 2007.

33. Centner, V.; Massart, D.; de Noord, O. E.; de Jong, S.; Vandeginste, B. M.; Sterna, C.; Anal. Chem. 1996, 68, 3851. 
Tabela 1S. Número de professores modulados por formação no ano de 2003

\begin{tabular}{|c|c|c|c|c|c|c|c|c|c|}
\hline $\mathrm{n}^{\mathrm{o}}$ & SRE & $\mathrm{DH}$ & HBM & $\mathrm{CT}$ & Q & $\mathrm{COL}$ & $\mathrm{NEN}$ & DFS & Total \\
\hline 1 & 110 Anápolis & 1 & 29 & 5 & 10 & 1 & 12 & 2 & 60 \\
\hline 2 & 120 Aparecida de Goiânia & 1 & 16 & 3 & 1 & 5 & 31 & 2 & 59 \\
\hline 3 & 140 Itapaci & 0 & 4 & 0 & 0 & 0 & 3 & 0 & 7 \\
\hline 4 & 150 Catalão & 0 & 5 & 4 & 0 & 0 & 7 & 5 & 21 \\
\hline 5 & 160 Ceres & 0 & 8 & 3 & 0 & 1 & 2 & 2 & 16 \\
\hline 6 & 180 Formosa & 0 & 22 & 0 & 0 & 0 & 6 & 0 & 28 \\
\hline 7 & 190 Goianésia & 1 & 15 & 0 & 0 & 0 & 5 & 3 & 24 \\
\hline 8 & 200 Inhumas & 0 & 8 & 0 & 1 & 3 & 5 & 0 & 17 \\
\hline 9 & 210 Goiás & 0 & 8 & 4 & 0 & 1 & 4 & 4 & 21 \\
\hline 10 & 220 Itapuranga & 0 & 5 & 2 & 0 & 0 & 1 & 3 & 11 \\
\hline 11 & 230 Iporá & 0 & 4 & 2 & 0 & 1 & 8 & 0 & 15 \\
\hline 12 & 240 Itaberaí & 0 & 5 & 0 & 0 & 0 & 1 & 0 & 6 \\
\hline 13 & 250 Itumbiara & 0 & 3 & 2 & 0 & 0 & 9 & 3 & 17 \\
\hline 14 & 260 Jataí & 0 & 3 & 1 & 0 & 0 & 10 & 3 & 17 \\
\hline 15 & 270 Jussara & 0 & 4 & 2 & 0 & 0 & 5 & 4 & 15 \\
\hline 16 & 280 Luziânia & 0 & 24 & 5 & 0 & 3 & 13 & 0 & 45 \\
\hline 17 & 290 Goiânia & 0 & 33 & 5 & 10 & 12 & 89 & 43 & 192 \\
\hline 18 & 300 Campos Belos & 0 & 4 & 0 & 0 & 1 & 1 & 1 & 7 \\
\hline 19 & 310 Morrinhos & 0 & 6 & 0 & 0 & 0 & 3 & 1 & 10 \\
\hline 20 & 320 Mineiros & 0 & 4 & 1 & 0 & 1 & 3 & 1 & 10 \\
\hline 21 & 330 Piranhas & 0 & 1 & 0 & 0 & 0 & 3 & 4 & 8 \\
\hline 22 & 340 Piracanjuba & 0 & 2 & 1 & 0 & 0 & 0 & 0 & 3 \\
\hline 23 & 350 Pires do Rio & 0 & 4 & 0 & 0 & 1 & 5 & 3 & 13 \\
\hline 24 & 360 Porangatu & 1 & 5 & 2 & 1 & 0 & 6 & 0 & 15 \\
\hline 25 & 370 Rubiataba & 0 & 8 & 2 & 0 & 1 & 1 & 0 & 12 \\
\hline 26 & 380 Posse & 0 & 14 & 0 & 0 & 0 & 1 & 0 & 15 \\
\hline 27 & 390 Quirinópolis & 0 & 3 & 0 & 1 & 0 & 6 & 5 & 15 \\
\hline 28 & 400 Rio Verde & 0 & 6 & 1 & 0 & 0 & 10 & 1 & 18 \\
\hline 29 & 410 São Luís de Montes Belos & 0 & 11 & 1 & 0 & 0 & 0 & 2 & 14 \\
\hline 30 & 420 Silvania & 0 & 3 & 2 & 0 & 2 & 4 & 0 & 11 \\
\hline 31 & 430 S M. do Araguaia & 0 & 7 & 0 & 0 & 0 & 4 & 0 & 11 \\
\hline 32 & 440 Trindade & 0 & 12 & 2 & 0 & 2 & 3 & 3 & 22 \\
\hline 33 & 450 Uruaçú & 0 & 11 & 2 & 0 & 0 & 1 & 2 & 16 \\
\hline 34 & 460 Palmeiras de Goiás & 0 & 16 & 1 & 0 & 0 & 2 & 1 & 20 \\
\hline 35 & 470 St. Hel. de Goiás & 0 & 8 & 0 & 0 & 1 & 1 & 2 & 12 \\
\hline 36 & 480 Goiatuba & 0 & 5 & 1 & 0 & 0 & 3 & 1 & 10 \\
\hline 37 & 490 Minaçú & 0 & 4 & 0 & 0 & 0 & 7 & 0 & 11 \\
\hline
\end{tabular}

*e-mail: elcana@quimica.ufg.br 
Tabela 2S. Número de professores modulados por formação no ano de 2007

\begin{tabular}{|c|c|c|c|c|c|c|}
\hline $\mathrm{n}^{\mathrm{o}}$ & SRE & HBM & Q & NEN & DFS & Total \\
\hline 1 & 110 Anápolis & 0 & 19 & 32 & 55 & 106 \\
\hline 2 & 120 Aparecida de Goiânia & 0 & 5 & 44 & 18 & 67 \\
\hline 3 & 140 Itapaci & 0 & 2 & 6 & 5 & 13 \\
\hline 4 & 150 Catalão & 0 & 0 & 10 & 31 & 41 \\
\hline 5 & 160 Ceres & 0 & 2 & 5 & 10 & 17 \\
\hline 6 & 180 Formosa & 0 & 2 & 18 & 7 & 27 \\
\hline 7 & 190 Goianésia & 0 & 2 & 8 & 17 & 27 \\
\hline 8 & 200 Inhumas & 0 & 0 & 15 & 2 & 17 \\
\hline 9 & 210 Goiás & 0 & 2 & 7 & 7 & 16 \\
\hline 10 & 220 Itapuranga & 1 & 0 & 1 & 12 & 14 \\
\hline 11 & 230 Iporá & 1 & 0 & 12 & 13 & 26 \\
\hline 12 & 240 Itaberaí & 3 & 0 & 0 & 7 & 10 \\
\hline 13 & 250 Itumbiara & 0 & 3 & 19 & 14 & 36 \\
\hline 14 & 260 Jataí & 0 & 1 & 16 & 7 & 24 \\
\hline 15 & 270 Jussara & 0 & 0 & 1 & 17 & 18 \\
\hline 16 & 280 Luziânia & 5 & 1 & 26 & 4 & 36 \\
\hline 17 & 290 Goiânia & 0 & 80 & 20 & 63 & 163 \\
\hline 18 & 300 Campos Belos & 0 & 0 & 5 & 0 & 5 \\
\hline 19 & 310 Morrinhos & 0 & 3 & 3 & 19 & 25 \\
\hline 20 & 320 Mineiros & 0 & 0 & 2 & 6 & 8 \\
\hline 21 & 330 Piranhas & 0 & 0 & 0 & 14 & 14 \\
\hline 22 & 340 Piracanjuba & 0 & 1 & 0 & 9 & 10 \\
\hline 23 & 350 Pires do Rio & 0 & 0 & 3 & 13 & 16 \\
\hline 24 & 360 Porangatu & 0 & 0 & 2 & 24 & 26 \\
\hline 25 & 370 Rubiataba & 0 & 1 & 8 & 6 & 15 \\
\hline 26 & 380 Posse & 0 & 3 & 4 & 15 & 22 \\
\hline 27 & 390 Quirinópolis & 0 & 2 & 0 & 26 & 28 \\
\hline 28 & 400 Rio Verde & 2 & 1 & 11 & 12 & 26 \\
\hline 29 & 410 São Luís de Montes Belos & 1 & 1 & 6 & 9 & 17 \\
\hline 30 & 420 Silvania & 1 & 5 & 0 & 9 & 15 \\
\hline 31 & 430 São Miguel do Araguaia & 0 & 0 & 0 & 11 & 11 \\
\hline 32 & 440 Trindade & 4 & 2 & 21 & 4 & 31 \\
\hline 33 & 450 Uruaçú & 1 & 2 & 7 & 10 & 20 \\
\hline 34 & 460 Palmeiras de Goiás & 3 & 0 & 8 & 10 & 21 \\
\hline 35 & 470 Santa Helena de Goiás & 0 & 1 & 6 & 6 & 13 \\
\hline 36 & 480 Goiatuba & 0 & 1 & 5 & 10 & 16 \\
\hline 37 & 490 Minaçú & 1 & 0 & 0 & 5 & 6 \\
\hline 38 & 170 Planaltina & 0 & 6 & 15 & 4 & 25 \\
\hline
\end{tabular}

